\title{
Current management of Herpes simplex infection in pregnant women and their newborn infants: What's hot and what's not
}

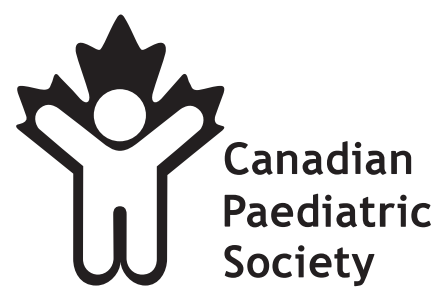

$\mathrm{N}$ eonatal disease due to Herpes simplex virus (HSV) is still of major concern. Our understanding of the epidemiology, pathogenesis and natural history of HSV disease has improved significantly in recent years. However, some aspects of this disease remain poorly understood. This note summarizes recent developments relating to the prevention, diagnosis, treatment and follow-up care of neonatal HSV infection.

\section{FEATURES OF NEONATAL HSV INFECTIONS}

Preliminary data suggest that in 2001 there were five proven cases of neonatal HSV infection per 100,000 live births in Canada (1). Neonates who have HSV infection are classified into three clinical categories: disseminated HSV infection, skin/eye/mouth (SEM) disease and central nervous system (CNS) disease. Vesicular skin lesions may be absent in a significant proportion of patients: $39 \%$ of neonates with disseminated disease, $32 \%$ with CNS disease and 17\% with SEM disease. Table 1 shows the proportions of infants in the above clinical categories who have abnormal outcomes $(2,3)$

PREVENTION OF NEONATAL HSV INFECTION

While transmission during labour and delivery accounts for $85 \%$ of cases of HSV infection in newborns, in utero (less than $5 \%$ ) and postnatal (less than 15\%) transmission may also occur. Women who have their first infection during pregnancy are more likely to transmit the infection than mothers who have reactivation of latent infection or a second infection with HSV 1 or HSV 2. The approach to the prevention of neonatal HSV infection is based on an understanding of the categories of maternal infection as they relate to the risk of transmission of HSV from mother to newborn as indicated below s(4).

Maternal infection and risk of transmission

Maternal infection may be classified as newly acquired or recurrent as follows:

Newly acquired

- First episode primary (mother is seronegative for HSV types 1 and 2 at the onset of infection)

- First episode nonprimary (mother has a new infection with one virus type, in the presence of antibodies to the other virus type)

\section{$\underline{\text { Recurrent }}$}

- Mother has preexisting antibodies to the virus type that has been isolated from the genital tract

Infants born to mothers who have true primary infections at the time of delivery are at the highest risk of acquiring HSV, with transmission rates of $50 \%$ or greater $(5,6)$. For infants born to mothers who have new infections that are nonprimary, the transmission rates are in the order of $30 \%$. The lowest risk of neonatal transmission occurs in the setting where the mother has an active infection that was acquired before pregnancy or at stages of gestation before the onset of labour. The attack rate for neonatal HSV in these infants is less than 2\% (4).

\section{Mode of delivery}

It has been recommended that a cesarean section should be performed if active lesions are present at the onset of labour (7). However, if the membranes have been ruptured for more than $6 \mathrm{~h}$, the benefit of a cesarean section has not been determined. A cesarean section reduces, but does not eliminate, the risk of newborn infection (5,7). A recent prospective cohort study suggested that a cesarean section delivery reduces the risk of HSV among newborns by $86 \%$ (8).

Role of suppressive therapy

Oral acyclovir given in the late third trimester has been suggested as a means of preventing recurrent genital HSV and possibly obviating the need for a cesarean section in women with genital herpes (9-12). Pregnant women with first episode HSV infections appear to benefit from acyclovir suppressive therapy (200 mg four times daily, starting one week before confinement). The evidence is weaker for women who have a history of genital HSV before pregnancy.

The use of acyclovir in pregnancy has given rise to several questions, some of which have been answered. Accumulating data suggest that there are no significant short term fetal and maternal adverse effects resulting from the use of acyclovir in late pregnancy (9). There are concerns, however, that the use of acyclovir may merely change the clinical scenario at delivery from one of symptomatic shedding to asymptomatic shedding of HSV. While there are no randomized trials to show definitively that this does not occur, the data available to date suggest that this is unlikely (9). Acyclovir resistance is unlikely to be a major concern given the expected short duration of acyclovir prophylaxis if the drug is started at 36 weeks. However, this is an area in need of further study, given a recent report indicating that an acyclovir-resistant mutant virus was observed in a neonate after only seven days of acyclovir in a setting where there was no maternal use of the drug (13).

The Hospital for Sick Children, Toronto, Ontario

Correspondence and reprints: Dr Upton Allen, The Hospital for Sick Children, 555 University Avenue, Toronto, Ontario M5G 1 X8.

Telephone 416-813-6273, fax 416-813-3404, e-mail upton.allen@sickkids.ca 
Table 1

Characteristics of neonatal Herpes simplex infection

\begin{tabular}{|c|c|c|c|}
\hline \multirow[b]{2}{*}{ Clinical features } & \multicolumn{3}{|c|}{ Clinical categories } \\
\hline & CNS & SEM & Disseminated \\
\hline Frequency (\%) & 34 & 34 & 32 \\
\hline Onset & 2-3 weeks & $7-10$ days & $1-2$ weeks \\
\hline $\begin{array}{l}\text { Percentage with skin } \\
\text { lesions at onset }(\%)\end{array}$ & 63 & 83 & 58 \\
\hline $\begin{array}{l}\text { Percentage with skin } \\
\text { lesions at any time (\%) }\end{array}$ & 68 & 83 & 61 \\
\hline CNS involvement (\%) & 100 & - & $60-70$ \\
\hline Mortality rate (\%) & 15 & 0 & 47 \\
\hline $\begin{array}{c}\text { Abnormal development } \\
\text { at } 1 \text { year of age }(\%)\end{array}$ & 70 & 2 & 25 \\
\hline
\end{tabular}

\section{MANAGEMENT OF THE EXPOSED ASYMPTOMATIC NEWBORN}

Infants whose mothers have a history of genital herpes, who were delivered vaginally or by cesarean section, and whose mothers do not have active genital lesions at the time of delivery, are at a very low risk of acquiring neonatal HSV infection. Such infants require no special evaluation during the newborn period. The following apply to infants whose mothers have active lesions at the time of delivery:

\section{Infants born by vaginal delivery}

Newborns who are exposed to HSV during labour and vaginal delivery and who are asymptomatic should have HSV cultures performed at $48 \mathrm{~h}$ after birth. In the unlikely scenario where such babies are discharged before $48 \mathrm{~h}$, they should be brought back for HSV cultures at $48 \mathrm{~h}$. Samples for HSV cultures should be taken from urine, mouth, eyes and nasopharynx. Some experts also recommend stool or rectal cultures. The use of a single swab for the eyes followed by the mouth and nasopharynx may reduce the number of swabs. Some experts recommend weekly surveillance cultures for four to six weeks to detect active viral replication before the frank manifestations of disease.

Empiric acyclovir at birth is recommended by most experts for asymptomatic infants who were delivered vaginally and whose mothers had proven or presumed primary infection. Some experts prefer waiting on the results of HSV cultures, or signs or symptoms of infection before initiating therapy. If therapy is being initiated, a cerebrospinal fluid (CSF) sample should be obtained before treatment. Acyclovir therapy is not recommended for the asymptomatic infants of mothers who had known recurrent genital lesions.

Infants born by cesarean delivery

Infants born by cesarean delivery, whose mothers had active herpetic lesions at delivery, should be observed carefully and cultured as above. Antiviral therapy is not routinely started for such infants who are asymptomatic, but such therapy should be initiated if culture results from the infants are positive for HSV or if HSV infection is strongly suspected.

\section{LABORATORY DIAGNOSIS}

HSV may be detected by viral cultures of the oropharynx, nasopharynx, stool, blood buffy coat, CSF and urine, poly- merase chain reaction (PCR) testing of CSF and blood, direct immunofluorescent antibody staining of skin lesions and enzyme immunoassays for HSV antigens. The utility of these testing modalities varies according to the type of sample that is being tested. It is very important for the clinician to speak with the virologist when cases of neonatal HSV are suspected.

Virus isolation by culture remains the definitive diagnostic method for neonatal HSV infection $(4,14)$. However, if skin lesions are present, rapid diagnostic techniques are of value, such as direct immunofluorescence for virus-infected cells and enzyme immunoassays for the presence of HSV antigens. Direct immunofluorescence staining is not reliable unless the sample was obtained from a skin lesion. Cells from oropharyngeal and CSF samples are not adequate for testing by direct immunofluorescence (4).

The isolation of virus from superficial cultures may represent colonization if such samples are obtained within the first $24 \mathrm{~h}$ after birth (4). If such cultures are positive more than 48 $\mathrm{h}$ after birth, they are likely to represent active viral replication and not colonization. Among exposed infants, data from prospective studies are lacking regarding the utility of regular surveillance cultures in the early diagnosis of neonatal HSV infection. An approach that is favoured by some experts is weekly cultures for the first four to six weeks of life as a guide to the need for acyclovir therapy (15).

While HSV cultures may be positive in infants with disseminated disease, in patients with localized CNS disease, CSF cultures are usually negative. For patients with localized CNS disease, PCR is an important diagnostic test. CSF DNA HSV PCR has obviated the need for brain biopsies in infants with presumed HSV CNS disease. However, since there is no commercially available HSV DNA PCR assay, the results of this test vary across laboratories (16-18). Due to this variability, caution should be exercised when using a negative CSF HSV PCR, to rule out HSV encephalitis, particularly if this decision is based on the results of a single lumbar puncture done in the early stages of the illness.

Patients without obvious clinical evidence of CNS disease should also have a lumbar puncture performed for CSF DNA HSV PCR, because some of these infants may have unrecognized CNS HSV infection. It has been well established that neonatal HSV CNS infection may occur despite the finding of 'normal' CSF cell counts and biochemical features, particularly during the early stages of infection. Thus, CSF HSV DNA PCR testing should still be performed even if the above parameters are normal.

Serological testing using HSV immunoglobulin M is usually not useful in the diagnosis of neonatal HSV infection. Each of the specific laboratory tests for HSV has important limitations. Thus, the results of these tests should be interpreted with careful consideration of the clinical picture and the results of general laboratory tests that may be consistent with HSV infection. These tests include electroencephalography, computerized tomography or magnetic resonance imaging, liver transaminases and complete blood count.

\section{TREATMENT AND FOLLOW-UP OF NEONATAL HSV INFECTION}

Acyclovir is the agent of choice for the treatment of neonatal HSV disease. Intravenous therapy is required, because oral acyclovir remains contraindicated for the treatment of HSV infections in neonates (19). Data are lacking on the use of newer 
agents such as famciclovir and valacyclovir in newborns. Recent data support the use of high-dose acyclovir $(60 \mathrm{mg} / \mathrm{kg} /$ day in three divided doses) for the treatment of neonatal HSV. Data from the National Institute of Allergy and Infectious Diseases Collaborative Study suggest that mortality and morbidity were lower in infants who were treated with higher doses of acyclovir (20).

Current data indicate that a 21 days duration of acyclovir rather than 14 days should be used to treat CNS and disseminated disease. The longer duration of therapy should always be used unless CNS infection is definitively ruled out. A repeat lumber puncture is recommended at the end of the treatment of CNS disease.

Given an association between late sequelae and recurrent HSV skin lesions, questions have arisen regarding the role of long term suppressive therapy with oral acyclovir. Administration of oral acyclovir as suppressive therapy can prevent recurrences of HSV after SEM disease (21). However, data are lacking regarding whether the suppression of cutaneous recurrences with oral acyclovir will result in a reduction in the incidence of late neurological sequelae (21).

Because there is the potential for significant neurological sequelae among survivors of neonatal HSV infection (2), careful follow-up of affected neonates is critical. They should have a structured follow-up program that allows for neurodevelopmental, ophthalmological and hearing assessments.

While relapses may occur after cessation of therapy, the optimal management of these recurrences is unclear. Infants with HSV infection should be followed and evaluated for recurrent disease and neurological sequelae. Such sequelae are most likely to occur among infants who were diagnosed with CNS or disseminated disease. Recurrent skin lesions are frequent in infants with neonatal HSV and may be associated with CNS sequelae if they occur during the first six months of life.

Finally, there are important infection control procedures that are required in the management of infants with neonatal HSV. Health care providers should work closely with their local infection control personnel to ensure that appropriate procedures are in place based on the most up to date guidelines.

\section{KEY POINTS}

While our understanding of HSV disease has improved, there are several goals yet to be achieved. This document summarizes important developments relating to the management of perinatal HSV infection.

- Women with primary HSV infections at delivery are at greatest risk of transmitting infection to their newborns;

- Newborns who are exposed to HSV during labour and vaginal delivery and who are asymptomatic should have HSV cultures performed at $48 \mathrm{~h}$ after birth. The isolation of virus from superficial cultures may represent colonization if such samples are obtained within the first $24 \mathrm{~h}$ after birth;

- Cesarean section reduces (in the order of $85 \%$ ), but does not eliminate the risk of newborn HSV infection;

- Oral acyclovir given in the late third trimester should be considered in high-risk women with gestational HSV infection as a means of preventing recurrent genital HSV, obviating the need for cesarean section and reducing the risk of neonatal transmission of HSV;

- PCR has emerged as the test of choice for diagnosing neonatal HSV CNS disease. Further development and standardization of PCR assays are required to determine the utility of this test on different body fluids. A negative PCR test does not rule out neonatal HSV infection of the CNS;

- CNS HSV infection may occur with normal CSF cell counts and biochemical parameters;

- High-dose acyclovir (60 mg/kg/day) is recommended for the treatment of neonatal HSV disease;

- The duration of acyclovir treatment for CNS and disseminated HSV is 21 days;

- While the administration of oral acyclovir as suppressive prophylaxis can prevent recurrences after SEM disease, it is unclear if oral acyclovir used in this manner will result in a reduction in the incidence of late neurological sequelae;

- Oral acyclovir is contraindicated for the treatment of HSV disease in newborns;

- Survivors of neonatal HSV infection should be followed closely in a structured program that enables adequate neurodevelopmental, ophthalmological and hearing assessments; and

- Close collaboration with the infection control team is required in the management of different clinical scenarios, including but not limited to neonates with HSV, neonates exposed during delivery, and women who are intrapartum or postpartum and who have active HSV lesions.

\section{REFERENCES}

1. Wong T. Neonatal Herpes simplex virus infection. Canadian Paediatric Surveillance Programme, 2001.

$<$ http://www.cps.ca/english/CPSP/ Studies/neoherpes.htm > (Version current at May 6, 2003)

2. Kimberlain DW, Lin C-Y, Jacobs RF, et al. The natural history of neonatal Herpes simplex virus infections in the acyclovir era. Pediatrics 2001;108:223-9.

3. Enright AM, Prober CG. Neonatal herpes infection: Diagnosis, treatment and prevention. Semin Neonatol 2002;7:283-91.

4. Arvin AM, Whitley RJ. Herpes simplex virus infections. In. Remington JS, Klein JO, eds. Infectious Diseases of the Fetus and Newborn, 5th ed. Philadelphia:WB Saunders Co, 2001:425-46.

5. Whitley RJ, Corey L, Arvin A, et al. Changing presentation of neonatal Herpes simplex virus infection. J Infect Dis 1988;158:109-16.

6. Brown ZA, Selke S, Zeh J, et al. The acquisition of Herpes simplex virus during pregnancy. N Engl J Med 1997;337:509-15.

7. Stone KM, Brooks CA, Guinan ME, et al. National surveillance for neonatal Herpes simplex virus infection. Sex Trans Dis 1989;16:152-6.

8. Brown ZA, Wald A, Morrows A, et al. Effect of serologic status and cesarean delivery on transmission rates of Herpes simplex virus from mother to infant. JAMA 2003;289:203-9.

9. Scott LL. Prevention of perinatal herpes: Prophylactic antiviral therapy. Clin Obstet Gynecol 1999;42:134-48.

10. Stray-Pedersen B. Acyclovir in late pregnancy to prevent neonatal Herpes simplex. Lancet 1990;336:756.

11. Scott LL, Hollier LM, McIntire D, Sanchez PJ, Jackson GL, Wendel GD. Acyclovir suppression to prevent clinical recurrences 
at delivery after first episode genital herpes in pregnancy: an openlabel trial. Infect Dis Obstet Gynecol 2001;9:75-80.

12. Randolph AG, Hartshorn RM, Washington AE. Acyclovir prophylaxis in late pregnancy to prevent neonatal herpes: A costeffectiveness analysis. Obstet Gynecol 1996;88:603-10.

13. Levin MJ, Weinberg A, Leary JJ, Sarisky RT. Development of acyclovir-resistant Herpes simplex virus early during the treatment of herpes neonatorum. Pediatr Infect Dis 2001;20:1094-7.

14. Whitley RJ. Herpes simplex viruses. In. Knipe D, Howley PM, eds. Fields Virology. Philadelphia: Lippincott-Raven, 1996: 2296-342.

15. Prober CG, Corey L, Brown ZA, et al. The management of pregnancies complicated by genital infections with Herpes simplex virus. Clin Infect Dis 1992;15:1031-8.

16. Kimberlain DW, Lakeman FD, Arvin AM, et al. Application of the polymerase chain reaction to the diagnosis and management of neonatal Herpes simplex virus disease. National Institute of Allergy ad Infectious Diseases Collaborative Study Group. J Infect Dis $1996 ; 174: 1162-7$.
17. Kimura $\mathrm{H}$, Futamura $\mathrm{M}$, Kito $\mathrm{H}$, et al. Detection of viral DNA in neonatal Herpes simplex virus infections: Frequent and prolonged presence in serum and cerebrospinal fluid. J Infect Dis 1991;164:289-93.

18. Troendle-Atksin J, Demmler GJ, Buffone GJ. Rapid diagnosis of herpes simplex virus encephalitis by using polymerase chain reaction. J Pediatr 1993;123:376-80.

19. American Academy of Pediatrics. Herpes simplex. In: Pickering LK, ed. 2000 Red Book: Report of the Committee on Infectious Diseases, 25th ed. Elk Grove Village: American Academy of Pediatrics, 2000:309-18.

20. Kimberlin DW, Jacobs RF, Powell DA, et al. The safety and efficacy of high-dose acyclovir in neonatal Herpes simplex virus infections. Pediatrics 2001;108:230-8.

21. Kimberlin D, Powell D, Gruber W, et al. Administration of oral acyclovir suppressive therapy after neonatal Herpes simplex virus disease limited to the skin, eyes and mouth: Results of a Phase 1/11 trial. Pediatr Infect Dis J 1996;15:247-54

\section{CANADIAN PAEDIATRIC SOCIETY, INFECTIOUS DISEASES AND IMMUNIZATION COMMITTEE}

Members: Drs Upton Allen, The Hospital for Sick Children, Toronto, Ontario; H Dele Davies, East Lansing, Michigan (USA); Simon Richard Dobson, BC's Children Hospital, Vancouver, British Columbia; Joanne Embree, The University of Manitoba, Winnipeg, Manitoba (Chair); Joanne Langley, IWK Health Centre, Halifax, Nova Scotia; Dorothy Moore, Montreal Children's Hospital, McGill University Health Centre, Montreal, Quebec; Gary Pekeles, Montreal Children's Hospital, Montreal, Quebec (Director Responsible)

Consultants: Drs Gilles Delage, Héma-Québec, Saint-Laurent, Quebec; Noni MacDonald, Dalhousie University, Halifax, Nova Scotia

Liaisons: Drs Scott Halperin, IWK Health Centre, Halifax, Nova Scotia (IMPACT); Susan King, The Hospital for Sick Children, Toronto, Ontario (Canadian Paediatrics AIDS Research Group); Larry Pickering, Centers for Disease Control and Prevention, Atlanta, Georgia

Principal author: Dr Upton Allen, The Hospital for Sick Children, Toronto, Ontario

The recommendations in this statement do not indicate an exclusive course of treatment or procedure to be followed. Variations, taking into account individual circumstances, may be appropriate. This article also appears in Can J Infect Dis 2003;14(4):197-200

This article originally appeared in Paediatrics $\mathbb{E}$ Child Health 2003;8(6):339-342. 